\title{
Comparison of Postoperative Quality of Life among Three Different Reconstruction Methods After Proximal Gastrectomy: Insights From the PGSAS Study
}

\author{
Hiroshi Yabusaki ${ }^{1}$ - Yasuhiro Kodera ${ }^{2}$ - Norimasa Fukushima ${ }^{3} \cdot$ Naoki Hiki $^{4}$ • \\ Shinichi Kinami ${ }^{5} \cdot$ Masashi Yoshida $^{6} \cdot$ Keishiro Aoyagi $^{7} \cdot$ Shuichi Ota $^{8} \cdot$ Hiroaki Hata $^{9}$. \\ Hiroshi Noro ${ }^{10} \cdot$ Atsushi Oshio $^{11} \cdot$ Koji Nakada $^{12}$
}

Published online: 6 June 2020

(C) The Author(s) 2020

\begin{abstract}
Background Proximal gastrectomy (PG) has become an increasingly preferred procedure for early cancer in the upper third of the stomach, owing to reportedly superior quality of life (QOL) after PG when compared with total gastrectomy. However, various methods of reconstruction have currently been proposed. We compared the postoperative QOL among the three different reconstruction methods after PG using the Postgastrectomy Syndrome Assessment Scale-45 (PGSAS-45) questionnaire.

Methods Post Gastrectomy Syndrome Assessment Study (PGSAS), a nationwide multi-institutional survey, was conducted to evaluate QOL using the PGSAS-45 among various types of gastrectomy. Of the 2,368 eligible data from the PGSAS survey, data from 193 patients who underwent PG were retrieved and used in the current study. The PGSAS-45 consists of 45 items including 22 original gastrectomy specific items in addition to the SF-8 and GSRS. These were consolidated into 19 main outcome measures pertaining postgastrectomy symptoms, amount of food ingested, quality of ingestion, work, and level of satisfaction for daily work, and the three reconstruction methods ( $n=193$; 115 esophago-gastrostomy [PGEG], 34 jejunal interposition [PGJI], and 44 jejunal pouch interposition [PGJPI]) were compared using PGSAS-45.

Results Size of the remnant stomach was significantly larger in PGEG, and significantly smaller in PGJI and PGJPI $(P<0.05)$. There was no difference in other patient background factors among the groups. EGJPI tended to be superior to PGEG in several of the 19 main outcome with marginal significance $(P=0.047-0.076)$.

Conclusion PGJPI appears to be the most favorable of the three reconstruction methods after PG especially when the size of remnant stomach is rather small.

Trial registration number UMIN-CTR \#000002116 entitled as "A study to observe correlation between resection and reconstruction procedures employed for gastric neoplasms and development of postgastrectomy syndrome"
\end{abstract}

Hiroshi Yabusaki

yabu@niigata-cc.jp

Yasuhiro Kodera

ykodera@med.nagoya-u.ac.jp

Norimasa Fukushima

fuku@ypch.gr.jp

Naoki Hiki

nhiki@med.kitasato-u.ac.jp

Shinichi Kinami

kinami@kanazawa-med.ac.jp
Masashi Yoshida

masashi@iuhw.ac.jp

Keishiro Aoyagi

keishiro@med.kurume-u.ac.jp

Shuichi Ota

shuichi.oota@noe.saiseikai.or.jp

Hiroaki Hata

hhata-kyt@umin.ac.jp

Hiroshi Noro

hiropsan@hotmail.com 


\section{Introduction}

Although the relative frequency of early gastric cancer existing on one-thirds of upper part of the stomach has been increasing $[1,2]$, no standard surgical procedure has been proposed based on robust clinical data [3, 4]. Recently, Postgastrectomy Syndrome Working Party (PGSWP), a voluntary group of Japanese surgeons focused on relieving postgastrectomy symptoms, progressed Postgastrectomy Syndrome Assessment Scale-45 (PGSAS-45), a tool evaluating patient reported outcome among patients who underwent gastrectomy [5]. A comparison of retrospective data between total gastrectomy (TG) and proximal gastrectomy (PG) using PGSAS-45 revealed superiority of PG over TG regarding several primary outcomes [6].

PG was defined by the Japanese gastric cancer treatment guidelines version 4 [7] as a modified gastrectomy and was proposed as an option for $\mathrm{CT} 1 \mathrm{cN} 0$ adenocarcinoma existing on one-thirds of upper part of the stomach provided over half of the distal stomach can be preserved. Considered as a function-preserving procedure, PG is now widely performed to improve postoperative quality of life (QOL). In truth, however, various reconstruction methods have been attempted following PG according to the preference of the surgeons, sometimes depending on factors such as the remnant stomach size. Reconstruction procedure ranges from esophago-gastrostomy (PGEG) [8, 9] usually with the anti-reflux methods (e.g., fundoplication or to create a His angle), to jejunal interposition method (PGJI) [10, 11], double tract method $[12,13]$, and jejunal pouch interposition method (PGJPI) $[14,15]$, of which the optimal method remains the matter of controversy.

The purpose of this study is to identify the most appropriate reconstruction method after PG using data from Postgastrectomy Syndrome Assessment Study

Atsushi Oshio

oshio.at@waseda.jp

Koji Nakada

nakada@jikei.ac.jp

1 Department of Gastroenterological Surgery, Niigata Cancer

Center Hospital, 2-15-3, kawagishicho, chuoku,

Niigata 951-8566, Japan

2 Department of Gastroenterological Surgery, Nagoya University Graduate School of Medicine, Nagoya, Japan

3 Department of Surgery, Yamagata Prefectural Central Hospital, Yamagata, Japan

4 Department of Upper Gastrointestinal Surgery, Kitasato University School of Medicine, Sagamihara, Kanagawa, Japan

5 Department of Surgical Oncology, Kanazawa Medical University, Kahoku, Ishikawa, Japan
(PGSAS) survey which is nationwide multi-institution surveillance of postgastrectomy patients in Japan using the PGSAS-45.

\section{Materials and methods}

\section{Patients and eligibility criteria}

Fifty-two institutions from all over Japan joined our surveillance. Questionnaire of the PGSAS-45 was delivered to 2,922 outpatients during from July 2009 to December 2010. Eligibility criteria were: (1) gastric cancer in stage IA or IB confirmed pathologically; (2) age from 20 to 75 years; (3) no experience of chemotherapy; (4) without recurrence or distant metastasis; (5) gastrectomy to be performed one year prior of the registration; (6) PS is 0 or 1 of ECOG; (7) sufficient ability to comprehend and answer to our forms; (8) without any medical record of other illnesses or previous surgical treatment that may affect their answers; (9) normal function of organs and mental state; and (10) supply of scripted informed consent. Patients with dual malignancy or concomitant resection of other organs (we permitted simultaneous resection equivalent for cholecystectomy) and we excepted those who underwent completion gastrectomy.

\section{Assessment of QOL}

The PGSAS-45 that developed newly consisted of the SF8; Short-Form Health Survey [16] and the GSRS; Gastrointestinal Symptom Rating Scale is a multi-dimensional QOL questionnaire [17]. The PGSAS-45 questionnaire

6 Department of Surgery, International University of Health and Welfare Hospital, Otawara, Tochigi, Japan

7 Department of Surgery, Kurume University School of Medicine, Kurume, Japan

8 Department of Surgery, Osaka Saiseikai - Noe Hospital, Osaka, Japan

9 Department of Surgery, National Hospital Organization, Kyoto Medical Centre, Kyoto, Japan

10 Department of Surgery, Japan Community Health Care Organization (JCHO), Osaka Hospital, Osaka, Japan

11 Faculty of Letters, Arts and Sciences, Waseda University, Shinjuku, Tokyo, Japan

12 Department of Laboratory Medicine, Jikei University School of Medicine, Minato, Tokyo, Japan 
includes 45 items, with 8 from the SF-8, 15 from the GSRS, and 22 original selected as clinically relevant by PGSWP (Table 1). The PGSAS-45 contains 23 items associated with postgastrectomy conditions (from 9 to 33), containing 15 from GSRS and 8 original.

Additionally, 12 items associated with intake of food, working, and satisfaction degree for daily life were assessed in this study. Food ingestion contains five regarding the ingested amount of oral intake (from 34 to 37,41 ) and three pertaining the property of ingestion (from 38 to 40). Another associated with working (42), and the remaining three pertain the satisfaction degree for everyday life (from 43 to 45$)$.

The twenty-three symptom items consist of a sevengrade Likert scale. All other excluding 1, 4, 29, 32, and 34-37 consist of a five-grade Likert scale. Higher scores point out better situations in 1-8, 34, 35 and 38-40. Conversely, higher scores point out worse situations in 9-28, $30,31,33$, and 41-45. The primary result scale was polished by reinforcement and excerption. Twenty-three items of symptom were merged into seven subscales (SS) of symptom by analyzing factors [6], as shown in Table 1. Evaluation contains score of total symptoms, quality of ingestion SS, dissatisfaction for daily life SS, physical component summary (PCS), and mental component summary (MCS) in the SF-8 as primary result scale. Furthermore, we picked up the data for primary result scale: weight change, quantity of food intake, requirement of additional food, ability to working, discontent about conditions, discontent about food, and discontent about working. Individual SS points signify average of draw up items, and average of seven symptom SS signifies the entire symptom points (Table 1).

\section{Methods of study}

We used a central registration system to register consecutive patients in this study. The questionnaire was delivered to all patients who are eligible when they visited to involved institutions. It is ordered for patients to turn back the format to the data center by mail. QOL data based on questionnaires were adapted to each enrolled data composed from case report forms. We registered this study in UMIN-CTR (No. 000002116). Approval of the Ethics Review Board was obtained in all institutions to participate PGSAS and submit data. Informed consent in writing was held from all enrolled cases.

\section{Statistical analysis of data}

To compare among the groups, the analysis of variance (ANOVA) and Fisher's exact test were used. In case the $P$ value was $<0.05$ in Fisher's test, residual analysis was added. In case the $P$ value of ANOVA was less than 0.1 , Tukey was conducted. When the $P$ values were $<0.1$ in Tukey, Cohen's $d$ was performed for the purpose of effect size. $P<0.05$ was considered statistically significant. Cohen's $d$ means the effect of the variable of individual cause: the effect size from 0.2 to 0.5 indicates a small difference clinically; from 0.5 to 0.8 indicates a moderate effect; and $\geq 0.8$ denotes a large effect clinically. Data analysis was conducted making use of JMP12.0.1 (SAS Institute Inc.).

\section{Results}

\section{Retrieving the questionnaire}

A total of 2,520 (86.2\%) questionnaires were screened, and 152 were thought to be not eligible for age over 75 years $(n=90)$, postoperative period within one year $(n=29)$, combined surgical removal $(n=8)$, and other causes $(n=25)$. Finally, 2,368 questionnaires $(81 \%)$ were determined to be eligible. PG was 193 cases in all 2,368, and among them, 115 cases were performed by PGEG, 34 cases by PGJI, and 44 cases by PGJPI (Fig. 1). Patient reported outcomes of these 193 cases were picked up for analyses.

\section{Characteristics of patient}

Characteristics of the 193 patients are shown in Table 2. There were no significant differences among patients receiving the three reconstruction methods regarding the background such as age, gender, postoperative period, approach, and preservation of the vagal celiac branch. However, about the size of remnant stomach, proportion of patients with the remnant stomach size greater than or equal to $2 / 3$ of the whole stomach was significantly larger in the PGEG (86.6\%) and significantly smaller in the PGJPI (14.3\%). In contrast, patients with the size of remnant stomach that amounted to around $1 / 2$ of the whole stomach were significantly more prevalent in the PGJPI (82.8\%) and PGJI (59.4\%) when compared with the PGEG $(13.4 \%)$.

\section{Assessments of QOL}

The analysis of the 19 primary result scale of PGSAS-45 was performed using ANOVA and Tukey (Table 3). The quality of ingestion SS was better in the PGJI significantly compared with the PGEG $(P=0.022$, Cohen's $d=0.57)$ and PGJPI $(P=0.050$, Cohen's $d=0.59)$ (Table 3$)$. The PGJPI showed better compared to the PGEG in several main outcome measures including food-related distress SS $(P=0.062, \quad$ Cohen's $\quad d=0.39), \quad$ constipation $\quad$ SS 
Table 1 Structure of Postgastrectomy Syndrome Assessment Scale (PGSAS)-45

\begin{tabular}{|c|c|c|c|c|c|}
\hline Domains & Items & & Items & & Subscales \\
\hline \multirow[t]{8}{*}{ QOL } & \multirow[t]{8}{*}{ SF-8 (QOL) } & 1 & Physical functioning* & $\begin{array}{l}\text { Five or six-point Likert } \\
\text { scale }\end{array}$ & $\begin{array}{l}\text { Physical component summary (PCS)* (item } \\
\text { 1-8) }\end{array}$ \\
\hline & & 2 & Role physical* & & $\begin{array}{l}\text { Mental component summary (MCS)* (item } \\
1-8)\end{array}$ \\
\hline & & 3 & Bodily pain* & & \\
\hline & & 4 & General health* & & \\
\hline & & 5 & Vitality* & & \\
\hline & & 6 & Social functioning* & & \\
\hline & & 7 & Role emotional* & & \\
\hline & & 8 & Mental health* & & \\
\hline \multirow[t]{25}{*}{ Symptoms } & \multirow[t]{15}{*}{ GSRS Symptoms) } & 9 & Abdominal pains & Seven-point Likert scale & $\begin{array}{l}\text { Esophageal reflux subscale (item } 10,11,13 \text {, } \\
\text { 24) }\end{array}$ \\
\hline & & 10 & Heartburn & Except item 29 and 32 & Abdominal pain subscale (item 9, 12, 28) \\
\hline & & 11 & Acid regurgitation & & Meal-related distress subscale (item 25-27) \\
\hline & & 12 & Sucking sensations in the epigastrium & & Indigestion subscale (item 14-17) \\
\hline & & 13 & Nausea and vomiting & & Diarrhea subscale (item 19, 20, 22) \\
\hline & & 14 & Borborygmus & & Constipation subscale (item 18, 21, 23) \\
\hline & & 15 & Abdominal distension & & Dumping subscale (item 30, 31, 33) \\
\hline & & 16 & Eructation & & \\
\hline & & 17 & Increased flatus & & Total symptom scale (above seven subscales) \\
\hline & & 18 & Decreased passage of stools & & \\
\hline & & 19 & Increased passage of stools & & \\
\hline & & 20 & Loose stools & & \\
\hline & & 21 & Hard stools & & \\
\hline & & 22 & Urgent need for defecation & & \\
\hline & & 23 & Feeling of incomplete evacuation & & \\
\hline & \multirow[t]{10}{*}{ Symptoms } & 24 & Bile regurgitation & & \\
\hline & & 25 & Sense of foods sticking & & \\
\hline & & 26 & Postprandial fullness & & \\
\hline & & 27 & Early satiation & & \\
\hline & & 28 & Lower abdominal pains & & \\
\hline & & 29 & $\begin{array}{l}\text { Number and type of early dumping } \\
\text { symptoms }\end{array}$ & & \\
\hline & & 30 & Early dumping general symptoms & & \\
\hline & & 31 & Early dumping abdominal symptoms & & \\
\hline & & 32 & Early dumping abdominal symptoms & & \\
\hline & & 33 & Late dumping symptoms & & \\
\hline \multirow{9}{*}{$\begin{array}{l}\text { Living } \\
\text { status }\end{array}$} & \multirow[t]{4}{*}{ Meals (amount) 1} & 34 & Ingested amount of food per meal* & & \\
\hline & & 35 & Ingested amount of food per day* & & \\
\hline & & 36 & Frequency of main meals & & \\
\hline & & 37 & Frequency of additional meals & & \\
\hline & \multirow[t]{3}{*}{ Meals(quality) } & 38 & Appetite* & Five-point Likert scale & Quality of ingestion subscale* (item 38-40) \\
\hline & & 39 & Hunger feeling* & & \\
\hline & & 40 & Satiety feeling* & & \\
\hline & Meals (amount) 2 & 41 & Necessity for additional meals & & \\
\hline & Social activity & 42 & Ability for working & & \\
\hline \multirow[t]{3}{*}{ QOL } & \multirow{3}{*}{$\begin{array}{l}\text { Dissatisfaction } \\
\quad(\mathrm{QOL})\end{array}$} & 43 & Dissatisfaction with symptoms & & \multirow{3}{*}{$\begin{array}{l}\text { Dissatisfaction for daily life subscale (item } \\
\text { 43-45) }\end{array}$} \\
\hline & & 44 & Dissatisfaction at the meal & & \\
\hline & & 45 & Dissatisfaction at working & & \\
\hline
\end{tabular}

In items or subscales with*; higher score indicating better condition. In items or subscales without*; higher score indicating worse condition. Each subscale is calculated as the mean of composed items or subscales except PCS or MCS of SF-8. Item 29 and 32 do not have score. Then, they were analyzed separately 


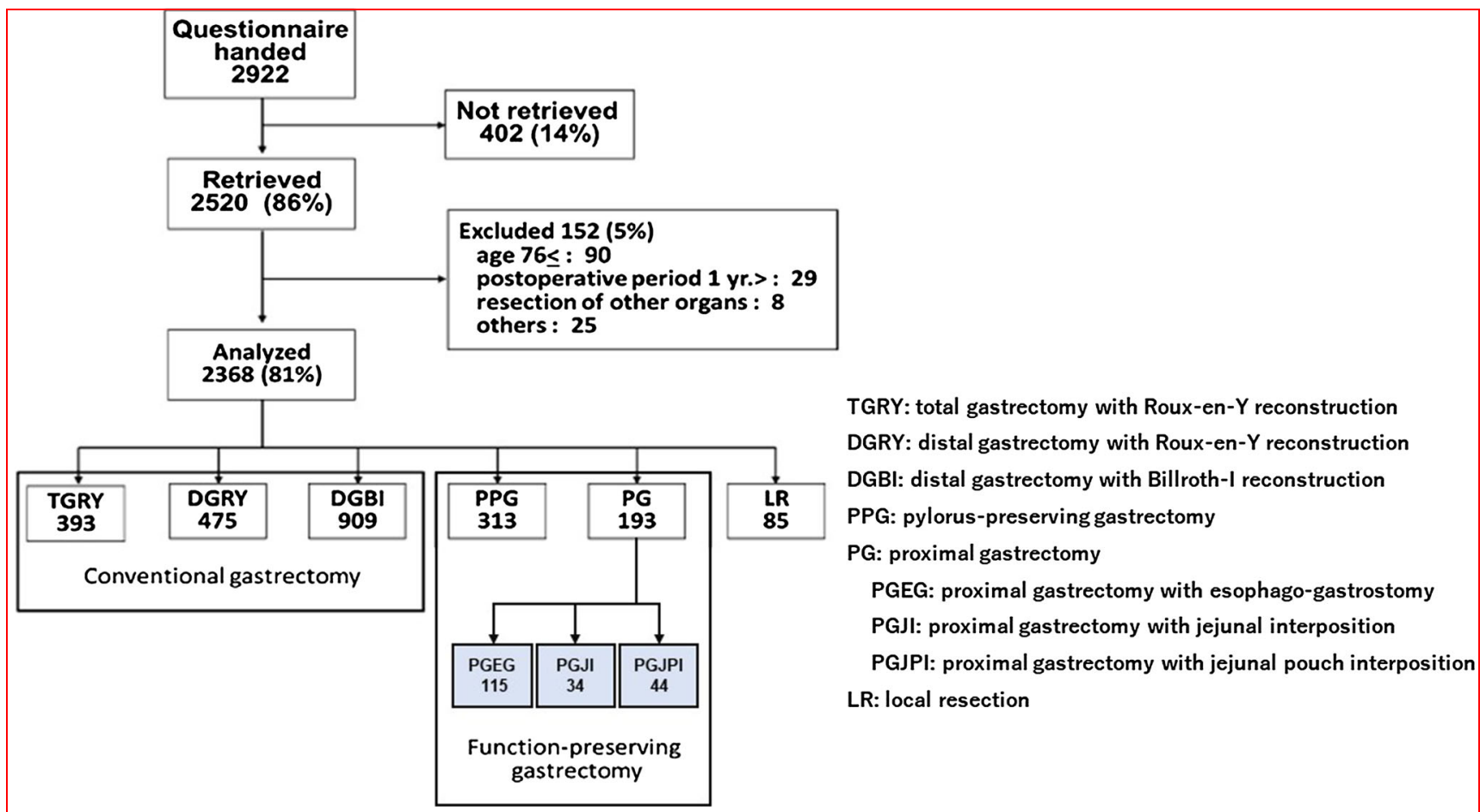

Fig. 1 Outline of this study

$(P=0.052$, Cohen's $d=0.42)$, dumping SS $(P=0.076$, Cohen's $d=0.40)$, dissatisfaction at working $(P=0.050$, Cohen's $d=0.42$ ), and dissatisfaction for dairy life SS $(P=0.047$, Cohen's $d=0.43)$ with marginal meaning (Table 3).

\section{Discussion}

The Japanese gastric cancer treatment guidelines version 4 proposed PG as selection for cT1cN0 adenocarcinoma existing on one-thirds of upper part of the stomach where over half of the distal stomach can be preserved [7], and PG has long been covered by the health insurance in Japan. Therefore, function-preserving PG is increasingly applied for them in Japan with the expectation of better QOL by preserving the both of secretion and motor activity of the remnant stomach. Additionally, importance of PG will increase more and more in the future with raising incidence of gastric cancer in early stage existing on one-thirds of upper part of the stomach. However, no prevailing consent exists regarding the optimal reconstructive method in PG with large-scale clinical trials at present $[4,18]$. It has been discussed for a long time whether PG was in any ways superior to TG as an operative procedure for early stage cancer existing on one-thirds of upper part of the stomach $[3,4]$. However, in a multicenter study focused on the analyses of self-entry-type questionnaire, PGSAS-45, for gastric cancer patients in early stage, superiority of PG over TG in terms of postgastrectomy QOL was clearly proven [6]. Nevertheless, some articles indicated that PGEG is associated with high risk of reflux esophagitis, while PGJI and PGJPI may cause stagnation in addition to occasional difficulties in the endoscopic examination of the remnant stomach $[19,20]$, postulating that $\mathrm{PG}$ should not be recommended unconditionally. To encounter these arguments, various reconstruction methods have been proposed for PG, but the debate for the optimal method continues. In the present study, we compared the postgastrectomy QOL after PG between three frequently performed methods: PGEG, PGJI, and PGJPI using the aforementioned PGSAS data. Although there was no remarkable difference among the groups, the outcome after PGJPI was marginally better in various aspects including meal-related distress SS, constipation SS, dumping SS, dissatisfaction at working, and dissatisfaction for dairy life SS despite the fact that a greater proportion of patients had small remnant stomach.

The results of a previous PGSAS study that focused on patients who received PGEG revealed that the size of remnant stomach certainly affected postgastrectomy QOL after PG, and the larger remnant stomach was associated with superior QOL [21]. Another article also pointed out the size of the remnant stomach as an important factor [22]. 
Table 2 Patients characteristics

\begin{tabular}{|c|c|c|c|c|}
\hline Reconstruction method & PGEG & PGJI & PGJPI & $P$-value \\
\hline Number & 115 & 34 & 44 & \\
\hline Age $(y r)^{\mathrm{a}}$ & $64.1 \pm 7.6$ & $64.6 \pm 7.3$ & $61.8 \pm 8.0$ & $0.190 \mathrm{a}$ \\
\hline Sex: Male/Female (N) & $88 / 27$ & $22 / 12$ & $29 / 14$ & $0.285 b$ \\
\hline Postoperative period $(\mathrm{mo})^{\mathrm{a}}$ & $37.8 \pm 26.1$ & $45.0 \pm 31.1$ & $43.9 \pm 29.7$ & $0.279 \mathrm{a}$ \\
\hline Approach: Laparoscopic/Open (N) & $17 / 98$ & $8 / 26$ & $8 / 35$ & $0.475 b$ \\
\hline \multicolumn{5}{|l|}{ preserved/not preserved $(\mathrm{N})$} \\
\hline \multicolumn{5}{|l|}{ Size of the remnant stomach: $N(\%)$} \\
\hline \multirow[t]{2}{*}{ Greater than or equal to $2 / 3$} & $97 \quad(86.6 \%)$ & $13 \quad(40.6 \%)$ & $5 \quad(14.3 \%)$ & $<0.001 \mathrm{~b}$ \\
\hline & $P=0.003 \mathrm{c}$ & $P=0.096 \mathrm{c}$ & \multicolumn{2}{|l|}{$P<0.001 \mathrm{c}$} \\
\hline \multirow[t]{2}{*}{ Around $1 / 2$} & $15 \quad(13.4 \%)$ & $19 \quad(59.4 \%)$ & $29 \quad(82.8 \%)$ & \\
\hline & $P<0.001 \mathrm{c}$ & $P=0.021 \mathrm{c}$ & $P<0.001 \mathrm{c}$ & \\
\hline \multirow[t]{2}{*}{ Less than or equal to $1 / 3$} & $0 \quad(0 \%)$ & $0 \quad(0 \%)$ & $1 \quad(2.9 \%)$ & \\
\hline & $P=0.429 \mathrm{c}$ & $P=0.672 \mathrm{c}$ & \multicolumn{2}{|l|}{$P=0.069 \mathrm{c}$} \\
\hline
\end{tabular}

${ }^{\mathrm{a}}$ Mean $\pm \mathrm{SD}$

a: ANOVA, b: Chi-square test, c: residual analysis

In the current study, although the remnant stomach size was significantly larger in the PGEG group with the proportion of more than two-thirds being as large as $86.6 \%$, patients who received PGJPI had superior results in several of the main outcome measures, including meal-related distress SS, constipation, dumping, dissatisfaction at working, and dissatisfaction for dairy life although the difference was marginal, possibly reflecting the small samples size of the PGJPI group. These results indicate that PGJPI is a candidate for the favorable reconstruction method that maintains better QOL, at least when the size of the remnant stomach is rather small as around a half of the whole stomach. Postgastrectomy syndrome appears strongly in proximal gastrectomy when the size of the remnant stomach is small, so quantity of diet is thought to be decreased. Whereas, in PGJPI, even if the real size of the remnant is small, retention ability that is equivalent to save a large remnant stomach is obtained by making substitute stomach. We consider this is one of the reasons why QOL of PGJPI was superior compared with PGEG in our study.

Recently, various new reconstruction methods or anastomotic procedures in PG such as double tract [12, 13], double-flap reconstruction, side overlap esophago-gastrostomy (SOFY) [23], and other original ingenuities of the surgeons are widely performed. We should continue to examine the usefulness of these new techniques until to determine the optimal reconstruction procedures in PG.

Limitations of this study include its retrospective design, wide variation in duration from surgery, and analysis with the limited number of cases. Despite efforts to analyze a large number of patients with PGSAS which eventually retrieved more than 2,000 questionnaires from 52 institutions, given the proportion of patients who undergo PG, only 193 could be used for the current analyses. Thus, the study was not sufficiently powered for some of the analyses. Additionally, the comparison between the three different reconstruction methods should have been biased by the fact that each surgeon or institution likely selected one's favorite reconstruction method [24-26]. For example, we cannot deny the possibility that the reconstruction method was selected according to the remnant stomach size at the discretion of the surgeon, and that led to the significant difference in that parameter between the three reconstruction methods. However, at the present time, there is no study that compared the different reconstruction methods after PG with comparable number of cases with the current study.

\section{Conclusion}

Although the differences in postoperative QOL among the three different reconstruction methods after PG were marginal, PGJPI was superior to PGEG in several main outcome measures of PGSAS-45 despite the fact that patients who underwent this mode of reconstruction had smaller remnant stomach. PGJPI could be a favorable reconstruction method after PG, especially when remnant size is relatively small. 
Table 3 Multiple comparison of postoperative QOL among PGEG, PGJI, and PGJPI

\begin{tabular}{|c|c|c|c|c|c|c|c|c|c|c|}
\hline & PGEG & $n=115$ & PGJI & $n=34$ & PGJPI & $n=44$ & ANOVA & Tukey & & \\
\hline & Mean & SD & Mean & SD & Mean & SD & $P$ value & & $P$ value & $\begin{array}{l}\text { Cohen's } \\
d\end{array}$ \\
\hline Esophageal reflux SS & 2.0 & 1.0 & 2.1 & 1.0 & 2.0 & 0.9 & 0.895 & & & \\
\hline Abdominal pain SS & 1.7 & 0.8 & 1.6 & 0.6 & 1.7 & 0.6 & 0.732 & & & \\
\hline Meal-related distress SS & 2.8 & 1.2 & 2.6 & 0.9 & 2.3 & 1.0 & 0.075 & $\begin{array}{l}\text { PGEG versus. } \\
\text { PGJPI }\end{array}$ & 0.062 & 0.39 \\
\hline Indigestion SS & 2.1 & 0.7 & 2.2 & 0.9 & 2.2 & 1.0 & 0.879 & & & \\
\hline Diarrhea SS & 2.0 & 1.1 & 1.9 & 0.9 & 1.8 & 0.8 & 0.372 & & & \\
\hline Constipation SS & 2.4 & 1.1 & 2.4 & 1.1 & 2.0 & 1.0 & 0.061 & $\begin{array}{l}\text { PGEG versus. } \\
\text { PGJPI }\end{array}$ & 0.052 & 0.42 \\
\hline Dumping SS & 2.2 & 1.1 & 1.9 & 0.7 & 1.8 & 0.9 & 0.053 & $\begin{array}{l}\text { PGEG versus. } \\
\text { PGJPI }\end{array}$ & 0.076 & 0.40 \\
\hline Total symptom score & 2.1 & 0.7 & 2.1 & 0.6 & 1.9 & 0.7 & 0.267 & & & \\
\hline Change in $\mathrm{BW}^{*}$ & -0.1 & 0.1 & -0.1 & 0.1 & -0.1 & 0.1 & 0.424 & & & \\
\hline $\begin{array}{l}\text { Ingested amount of food per } \\
\text { meal* }\end{array}$ & 6.4 & 2.0 & 6.8 & 1.8 & 6.5 & 1.8 & 0.489 & & & \\
\hline Necessity for additional meals & 2.0 & 0.8 & 2.2 & 0.8 & 1.9 & 0.8 & 0.295 & & & \\
\hline \multirow[t]{2}{*}{ Quality of ingestion SS* } & 3.5 & 1.0 & 4.0 & 0.8 & 3.5 & 1.0 & 0.022 & $\begin{array}{l}\text { PGJI versus. } \\
\text { PGJPI }\end{array}$ & 0.050 & 0.59 \\
\hline & & & & & & & & $\begin{array}{l}\text { PGJI versus. } \\
\text { PGEG }\end{array}$ & 0.022 & 0.57 \\
\hline Ability for working & 2.1 & 0.9 & 1.8 & 0.8 & 1.8 & 0.9 & 0.221 & & & \\
\hline Dissatisfaction with symptoms & 2.1 & 1.0 & 2.0 & 0.9 & 1.8 & 0.7 & 0.169 & & & \\
\hline Dissatisfaction at the meal & 2.8 & 1.1 & 2.7 & 1.1 & 2.5 & 1.1 & 0.259 & & & \\
\hline Dissatisfaction at working & 2.2 & 1.1 & 2.1 & 1.0 & 1.7 & 1.0 & 0.060 & PGEG vs. PGJPI & 0.050 & 0.42 \\
\hline Dissatisfaction for daily life SS & 2.3 & 0.9 & 2.2 & 0.8 & 2.0 & 0.8 & 0.060 & PGEG vs. PGJPI & 0.047 & 0.43 \\
\hline PCS of SF-8* & 49.3 & 6.3 & 50.5 & 5.2 & 49.4 & 6.3 & 0.610 & & & \\
\hline MCS of SF-8* & 48.9 & 5.8 & 49.0 & 5.3 & 49.4 & 6.9 & 0.895 & & & \\
\hline
\end{tabular}

Acknowledgments The authors thank all physicians who participated in this study and the patients whose cooperation made this study possible.

Funding Funding was provided by The Jikei University and the Japanese Society for Gastro-surgical Pathophysiology.

\section{Compliance with ethical standards}

Conflict of interest The authors have no conflicts of interest to declare.

Informed consent Written informed consent was obtained from all enrolled patients.

Open Access This article is licensed under a Creative Commons Attribution 4.0 International License, which permits use, sharing, adaptation, distribution and reproduction in any medium or format, as long as you give appropriate credit to the original author(s) and the source, provide a link to the Creative Commons licence, and indicate if changes were made. The images or other third party material in this article are included in the article's Creative Commons licence, unless indicated otherwise in a credit line to the material. If material is not included in the article's Creative Commons licence and your intended use is not permitted by statutory regulation or exceeds the permitted use, you will need to obtain permission directly from the copyright holder. To view a copy of this licence, visit http://creativecommons. org/licenses/by/4.0/.

\section{References}

1. Salvon-Harman JC, Cady B, Nikulasson S et al (1994) Shifting proportion of gastric 2 adenocarcinomas. Arch Surg 129:381-389

2. Okabayashi T, Gotoda T, Kondo H et al (2000) Early carcinoma of the gastric cardia 4 in Japan: is it different from that in the west? Cancer 89:2555-2559

3. Masuzawa T, Takiguchi S, Hirao M et al (2014) Comparison of perioperative and 6 long-term outcome of total and proximal gastrectomy for early gastric cancer: a multi-7 institutional retrospective study. World J Surg 38:1100-1106. https://doi.org/10. 1007/s00268-013-2370-5

4. Nakamura M, Yamaue H (2016) Reconstruction after proximal gastrectomy for gastric cancer in the upper third of the stomach: a review of the literature published from 2000 to 2014. Surg Today $46: 517-527$ 
5. Nakada K, Ikeda M, Takahashi M et al (2015) Characteristics and clinical relevance of post-gastrectomy syndrome assessment scale (PGSAS)-45: newly developed 13 integrated questionnaires for assessment of living status and quality of life in post-14 gastrectomy patients. Gastric Cancer 18:147-158

6. Takiguchi N, Takahashi M, Ikeda M et al (2015) Long-term quality-of-life comparison of total gastrectomy and proximal gastrectomy by Postgastrectomy Syndrome Assessment Scale (PGSAS-45): a nationwide multi-institutional study. Gastric Cancer 18:407-416

7. Japanese Gastric Cancer Association (2017) Japanese gastric cancer treatment guidelines 2014 (Ver. 4). Gastric Cancer 20(1):1-19

8. Hirai T, Matsumoto H, Iki K et al (2006) Lower-esophageal sphincter-and vagus - preserving proximal partial gastrectomy for early cancer of gastric cardia. Surg Today 36:874-878

9. Okabe H, Obama K, Tanaka E et al (2013) Laparoscopic proximal gastrectomy with $\mathrm{s}$ hand-sewn esophago-gastric anastomosis using a knifeless endoscopic linear stapler. Gastric Cancer 10:268-274

10. Nomura E, Lee SW, Tokuhara T et al (2012) Functional outcomes according to the size of the gastric remnant and type of reconstruction following open and laparoscopic proximal gastrectomy for gastric cancer. Hepatogastroenterology 59:1677-1681

11. Isobe T, Hashimoto K, Kizaki J et al (2014) Reconstruction methods and complications in proximal gastrectomy for gastric cancer, and a comparison with total gastrectomy. Kurume Med J 61:23-29

12. Aikou T, Natsugoe S, Shimazu H et al (1988) Antrum preserving double tract method for reconstruction following proximal gastrectomy. Jpn J Surg 18:114-115

13. Nomura E, Lee SW, Kawai M et al (2014) Functional outcomes by reconstruction technique following laparoscopic proximal gastrectomy for gastric cancer: double tract versus jejunal interposition. World J Surg Oncol. 12:20. https://doi.org/10.1186/ 1477-7819-12-20

14. Kameyama J, Ishida H, Yasaku Y et al (1993) Proximal gastrectomy reconstructed by interposition of a jejunal pouch. surgical technique. Eur J Surg 159:491-493

15. Takeshita K, Saito N, Saeki I et al (1997) Proximal gastrectomy and jejunal pouch interposition for the treatment of early cancer in the upper third of the stomach; surgical techniques and evaluation of postoperative function. Surgery 121:278-286
16. Turner-Bowker DM, Bayliss MS, Ware JE Jr et al (2003) Usefulness of the SF-8 health survey for comparing the impact of migraine and other conditions. Qual Life Res 12:1003-1012

17. Svedlund J, Sjodin I, Dotevall G (1988) GSRS: a clinical rating scale for gastrointestinal symptoms in patients with irritable bowel syndrome and peptic ulcer disease. Dig Dis Sci 33:129-134

18. Ahn SH, Jung DH, Son SY et al (2014) Laparoscopic double-tract proximal gastrectomy for proximal early gastric cancer. Gastric Cancer 17:562-570

19. Katai H, Morita S, Saka M et al (2010) Long-term outcome after proximal gastrectomy with jejunal interposition for suspected early cancer in the upper third of the stomach. Br J Surg 97:558-562

20. Kumagai K, Shimizu K, Yokoyama N et al (2012) Questionnaire survey regarding the current status and conventional issues concerning reconstruction after gastrectomy in Japan. Surg Today 42:411-418

21. Inada T, Yoshida M, Ikeda M et al (2014) Evaluation of QOL after proximal gastrectomy using a newly developed assessment scale (PGSAS-45). World J Surg 38:3152-3162. https://doi.org/ 10.1007/s00268-014-2712-y

22. Nomura E, Isozaki H, Fujii K (2003) Postoperative evaluation of function-preserving gastrectomy for early gastric cancer. Hepatogastroenterology 50:2246-2250

23. Yamashita Y, Yamamoto A, Tamamori Y et al (2017) Side overlap esophagogastrostomy to prevent reflux after proximal gastrectomy. Gastric Cancer 20(4):728-735

24. Ichikawa D, Komatsu S, Okamoto K et al (2013) Evaluation of symptoms related to reflux esophagitis in patients with esophagogastrostomy after proximal gastrectomy. Langenbecks Arch Surg 398:697-701

25. Tokunaga M, Hiki N, Ohyama S et al (2009) Effects of reconstruction methods on a patient's quality of life after a proximal gastrectomy: subjective symptoms evaluation using questionnaire survey. Langenbecks Arch Surg 396:637-641

26. Kuwabara K, Matsuda S, Fushimi K et al (2012) Comparative study on the difference in functional outcomes at discharge between proximal and total gastrectomy. Case Rep Gastroenterol $6: 400-409$

Publisher's Note Springer Nature remains neutral with regard to jurisdictional claims in published maps and institutional affiliations. 